\title{
Metástasis cutánea de carcinoma de células renales.
}

\author{
García Torrelles M, Beltrán Armada JR, Verges Prosper A, Santolaya García JI, \\ Espinosa Ruiz JJ*, Tarín Planes M, Sanjuán de Laorden C. \\ Servicio de Urología, y *Servicio de Dermatología, Hospital Universitario Dr. Peset, Valencia.
}

Actas Urol Esp. 2007;31(5):556-558

\section{RESUMEN}

\section{METÁSTASIS CUTÁNEA DE CARCINOMA DE CÉLULAS RENALES}

El carcinoma de células renales se caracteriza por su evolución impredecible. Presentamos un caso clínico de aparición de metástasis cutánea de carcinoma renal de células claras con pronóstico ominoso, tras cinco años de tratamiento quirúrgico curativo del primario renal. Revisamos la literatura e incidimos en la necesidad de un seguimiento prolongado y exhaustivo en estos pacientes.

Palabras clave: Carcinoma de células renales. Metástasis cutánea. Cirugía.

\section{ABSTRACT \\ CUTANEOUS METASTASES OF RENAL CELL CARCINOMA}

Renal cell carcinoma has an unknown evolution. We report a case of a man with a skin metastases from renal cell carcinoma and an unfortunate result, five years after its radical surgical treatment. We review the literature and emphasize the need of a long and exhaustive surveillance in these patients.

Keywords: Renal cell carcinoma. Skin metastases. Surgery.

$\mathrm{E}^{1}$ carcinoma de células renales (CCR) se caracteriza por una evolución impredecible, determinada por su agresividad biológica. Todavía desconocemos cuáles son los verdaderos factores pronósticos que condicionan su evolución, aunque la respuesta parece hallarse en las alteraciones genéticas moleculares específicas de cada tumor, hacia donde se están encaminando todos los esfuerzos en los últimos estudios. Un ejemplo de este desconocimiento es la aparición de metástasis en algunos CCR muchos años después de una cirugía curativa, de un tumor renal incluso histológicamente bien diferenciado. Presentamos un caso y revisamos la literatura.

\section{CASO CLÍNICO}

Presentamos un varón de 60 años de edad diagnosticado de masa renal incidental compati- ble con carcinoma renal en polo inferior de riñón derecho de 5x5cm (Fig. 1), con estudio de extensión negativo al que se le realizó una nefrectomía radical derecha con dictamen histopatológico de carcinoma de células renales de células claras de bajo grado, Estadio I.

A los cinco años de la intervención acude al dermatólogo por una lesión cutánea en área parietal izquierda de crecimiento progresivo de aspecto nodular eritematoso con algunas zonas queratósicas de base discretamente pediculada de seis meses de evolución. Se lleva a cabo su rebanado y electrocoagulación ante la sospecha de angioma capilar versus botriomicoma (Fig. 2). El diagnóstico histológico revela infiltración dérmica por carcinoma de células renales de bajo grado citológico compatible con metástasis de primario renal por lo que se completa su exéresis

Abreviaturas: CCR: Carcinoma de células renales. EMA: Antígeno epitelial de membrana. TC: Tomografia computerizada. CEA: Antígeno carcino-embrionario. H-E: Hematoxilina-eosina. 


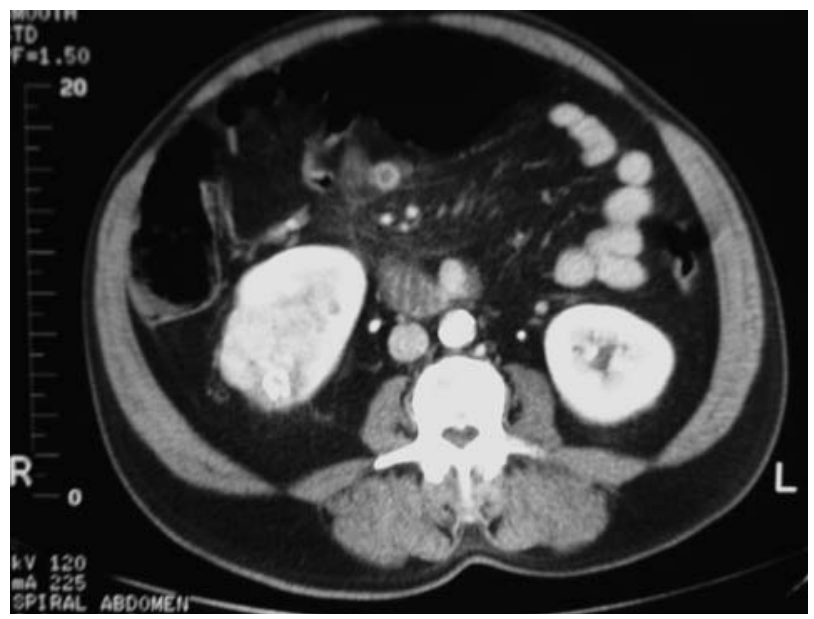

FIGURA 1. TC abdominal. Neoformación heterogénea que capta contraste en riñón derecho.

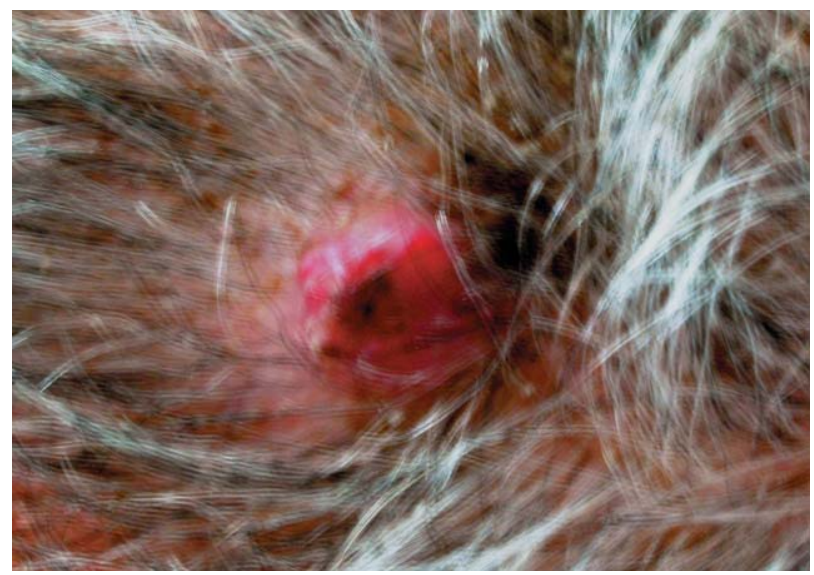

FIGURA 2. Aspecto de la lesión cutánea en cuero cabelludo tras el rebanado.

(Figs. 3 y 4). A los 7 meses presenta múltiples focos de hipernefroma en riñón izquierdo y nódulos en páncreas evolucionando en los siguientes meses a un cuadro de deterioro neurológico progresivo provocado por múltiples lesiones metastásicas cerebrales, así como aumento de las metástasis preexistentes y aparición de otras en territorio torácico falleciendo 15 meses tras el diagnóstico de la metástasis cutánea de carcinoma de células claras.

\section{DISCUSIÓN}

Pese al aumento del número de casos de CCR diagnosticados incidentalmente en las últimas décadas, generalmente estadios tempranos, la enfermedad diseminada aparece en un porcentaje elevado no deseable. Entre el $10-45 \%$ de CCR presentan metástasis a distancia en el momento del diagnóstico, y el 40\% metástasis a distancia en su evolución. Las más frecuentes en pulmón, hueso y riñón contralateral ${ }^{1,2}$. Siendo menos frecuentes pero no excepcionales metástasis a piel que se recogen entre un $2,8-6,8 \%$ de $\mathrm{CCR}^{1}$.

La identificación de metástasis de CCR a piel no la suele realizar el urólogo por el bajo índice de sospecha ante estas lesiones cutáneas que normalmente suelen asemejarse a trastornos dermatológicos comunes ${ }^{3}$, y en ocasiones dado el largo intervalo de tiempo desde la nefrectomía hasta la aparición de la lesión no se relaciona el tumor primario en su etiopatogenia ${ }^{2}$.

La afectación metastásica a piel de tumores urológicos primarios es menor que para otras neoplasias, representando la tercera fuente tras los tumores de mama y pulmón ${ }^{4}$. Se ha notificado

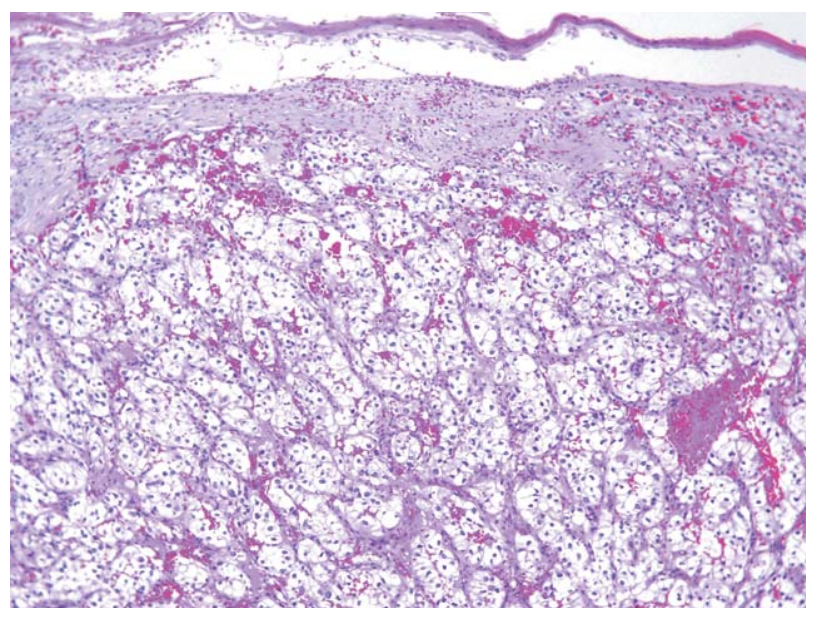

FIGURA 3. (H-E 10x) Se observa a nivel de dermis un nódulo constituido por células claras de núcleo redondo con nucleolos, formando nidos separados por estroma conectivo muy vascularizado.

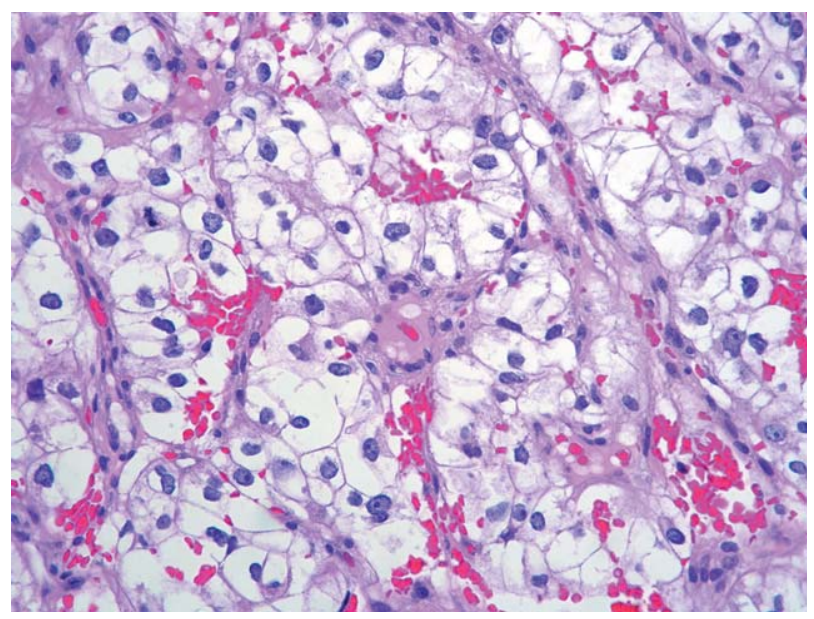

FIGURA4. (H-E 40x) Detalle de la Figura 3. 
para los tumores renales en un 3,4\% de los casos, para tumores vesicales en el $0,84 \%$, y para tumores de próstata y testes en un $0,36 \%$ y $0,4 \%$ respectivamente ${ }^{3}$. Son más frecuentes en varones ${ }^{5}$. La localización de las metástasis cutáneas tiene lugar fundamentalmente a nivel de cabeza, cuello $\mathrm{y}$ tronco en este orden. Suelen ser lesiones únicas que varían de unos milímetros a unos centímetros de diámetro, en forma de nódulos subcutáneos bien delimitados o placas infiltrantes rosadas o rojas de crecimiento rápido, indoloros y sin tendencia a ulcerarse. Al microscopio se aprecia un patrón de crecimiento celular irregular con infiltración por células epiteliales con numerosas atipias y mitosis celulares, zonas de necrosis y hemorragia. Las técnicas de inmunohistoquimia demuestran positividad para marcadores epiteliales, keratina, EMA, CEA, y vimentina. Los estudios inmunohistoquímicos aclaran la naturaleza de las lesiones sobre todo en aquellos pacientes en los que el tumor renal primario no se ha diagnosticado y en los que las metástasis cutáneas no presentan parecido con el tumor primario por la indiferenciación celular y anaplasia ${ }^{3,6}$.

En la mayoria de los pacientes las metástasis cutáneas del CCR aparecen en un estadio tardío de la enfermedad, años después tras la nefrectomía de un tumor órgano-confinado, y en ocasiones pueden aparecer con antelación al diagnóstico del tumor renal ${ }^{6-8}$. En general, se consideran una manifestación tardía de la enfermedad de mal pronóstico asociándose hasta en un $90 \%$ de los casos a metástasis viscerales sincrónicas ${ }^{7}, \mathrm{y}$ con una supervivencia tumoral específica en general menor a 6 meses $^{2,3,8}$.

Para el CCR diseminado carecemos de opciones terapéuticas eficaces para la enfermedad diseminada. Para el tratamiento paliativo de las metástasis cutáneas se pueden proponer la excisión quirúrgica de lesiones cutáneas solitarias, radioterapia sola o combinada con cirugía, o la inyección intralesional de agentes terapéuticos como el interferón ${ }^{1,3}$.

Es fundamental el diagnóstico diferencial con otras lesiones histológicamente similares de naturaleza benigna, inflamatoria y maligna, de diferente pronóstico. Entre ellas destacamos el dermatofibroma de células claras, el granuloma piógeno, reacciones xantogranulomatosas, el melanoma, y el sarcomas de células claras $^{9,10}$, con las que comparte serias dificultades diagnósticas en el estudio histopatológico clásico siendo necesario el uso de técnicas de inmunohistoquimia. Así Kouroupakis diagnostica con inmunohistoquimia nueve metástasis cutáneas de $\mathrm{CCR}^{6}$. Por otro lado, el análisis citogenético es otra técnica diagnóstica complementaria útil, que puede aportar el diagnóstico definitivo cuando las técnicas inmunohistoquímicas y de microscopia electrónica son insuficientes ${ }^{11}$.

Es interesante, por lo tanto, destacar que ante la presencia de una metástasis cutánea de CCR la historia clínica puede no aportar ningún dato relevante, que el diagnóstico histológico sólo no es sencillo requiriendo técnicas específicas y que la aparición de metástasis cutáneas del CCR es sin lugar a dudas un signo de mal pronóstico. Es necesario incluir en los protocolos de pacientes diagnosticados de CCR el examen de la piel en el seguimiento, el cual además debe ser prolongado, y ante la aparición de una lesión cutánea en estos pacientes hay que pensar en la posibilidad de una metástasis cutánea de CCR.

\section{REFERENCIAS}

1. Persi K, Fargnoli MC, Lunghi F, Chimenti S. Unusually large cutaneous metastases of renal cell carcinoma. Acta Derm Venereol. 2001 JanFeb;81(1):77-78.

2. Aridogan IA, Satar N, Doran E, Tansung MZ. Scrotal skin metastases of renal cell carcinoma: a case report. Acta Chir Belg 2004;104(5):599-600.

3. Mueller TJ, Wu H, Greenberg RE, Hudes G, Topham N, Lessin SR, et al. Cutaneous metastases from genitourinary malignancies. Urology. 2004;63(6):1021-1026.

4. Pertusa Peña C, Llarena Ibarguren R, Zabala Egurrola JA, Arruza Echevarria A. Metástasis cutáneas como primer sintoma del adenocarcinoma renal. Arch Esp Urol 1988;41(7):541-542.

5. Paez Borda A, Nacarino Corbacho L, Diego Garcia A, Prieto Chaparro L, Delgado Martin JA, Salinas Casado J, et al. Metástasis cutáneas y ginecológicas reveladoras del carcinoma de células renales: Implicaciones diagnósticas y terapéuticas. Arch Esp Urol 1992;45(4):341-345.

6. Kouroupakis D, Patsea E, Sofras F, Apostolikas N. Renal cell carcinoma metastases to the skin: a not so rare case?. Br J Urol 1995;75(5):583-585.

7. Dorairajan LN, Hemal AK, Aron M, Rajeev TP, Nair M, Seth A, et al. Cutaneous metastases in renal cell carcinoma. Urol Int 1999;63(3):164167.

8. Koga S, Tsuda S, Nishikido M, Matsuya F, Saito Y, Kanetake H. Renal cell carcinoma metastatic to the skin. Anticancer Res 2000;20(3B):1939 1940 .

9. Wambacher-Gasser B, Zelger B, Zelger BG, Steiner H. Clear cell dermatofibroma. Histopathology 1997;30(1):64-69.

10. Zelger BW, Steiner H, Kuntzner H. Clear cell dermatofibroma. Case report of an unusual fibrohistiocytic lesion. Am J Surg Pathol 1996;20(4):483491.

11. Amo-Takyi BK, Handt S, Gunawan B, Hollweg HG, Fuzesi L. A cytogenetic approach to the differential diagnosis of metastatic clear cell renal carcinoma. Histopathology 1998;32(5):436-443.

Correspondencia autora: Dra. M. García Torrelles

Servicio de Urología. Hospital Universitario Dr. Peset. Av. Gaspar Aguilar, 90 - 46017 Valencia. Telf. 963861903

E-mail autora: garcia_martor@gva.es

Información artículo: Nota clínica

Trabajo recibido: marzo 2006

Trabajo aceptado: mayo 2006 